\title{
Utilization of Local Available Materials to Stabilize Native Soil (Earth Roads) in Tanzania-Case Study Ngara
}

\author{
Fikiri Fredrick Magafu, Wu Li \\ Faculty of Civil Engineering, China university of Geosciences, Wuhan, China \\ E-mail: fikirimagafu@yahoo.co.uk,lwu@cug.edu.cn \\ Received March 5, 2010; revised March 5, 2010; accepted May 10, 2010
}

\begin{abstract}
The native soil behavior of unpaved low volume roads and their mode of failure were studied to establish proper method of stabilizing native soils using local available materials. The use of lime and its positive effect to modify and stabilize Ngara soil in Tanzania is presented in this paper. There are many methods of stabilizing soil to gain required engineering specifications. These methods range from mechanical to chemical stabilization. Most of these methods are relatively expensive to be implemeted by slowly developing nations and the best way is to use locally available materials with relatively cheap costs affordable by their internal funds. Tanzania is a country having abundantly amount of Lime. Ngara native soil roads (unpaved rural roads) was studied under preliminary investigation and found to have higher plasticity, tendency of swelling and shrinking, low bearing capacity when wet, compressive strength of soil to have higher sensitivity to moisture and lower shear strength when wet. These soil behaviors deny road access to about 32 million people in Tanzania (80\% of population) during rainy season. The detailed investigations is still going on at China university of Geosciences but other results from similar researches show that Ngara soils can be stabilized by lime and gain the required engineering properties.
\end{abstract}

Keywords: Low Volume Roads, Higher Plasticity Index, Bearing Capacity, Shear Strength of Soil, Engineering Properties of Soils, Engineering Specifications, Swell and Shrinkage

\section{Introduction}

Road Fund Board of Tanzania was established in 1997 with the responsibility of collecting and disbursement of internal funds to road agents for road maintenance activities. Tanzania is a slowly developing nation having a total road network of 85,525 [1] kilometers out of which only 5,034 kilometers is paved. Low volume rural roads consist of 56,625 kilometers which is unpaved and hardly passable throughout a year and serves more than $80 \%$ of Tanzanian population [2] (about 32 million people).

Every place has its own definition of low volume roads depending on social economic development of the area. For developing countries, low volume roads are those roads carrying less than 0.5 million equivalent standard axle [3]. In reality the research conducted by Southern African Development Community (SADC) shows that in Tanzania low volume rural roads carries less than 0.1 million equivalent standard axle during design period.

In this paper, as for the case of Ngara District in Tan- zania, low volume roads are those district and village roads that carry less than 0.1 million equivalent standard axle of traffic during their design period. In actual, Ngara district rural roads carry less than 0.05 millions standard equivalent axle according to 2008 traffic count data analysis [4]. The design period is 10 years.

The engineering properties of native soil where unpaved roads pass through are critical parameters in the ability of road to carry and safely distribute stresses imposed upon it without failure. The failure of Ngara low volume roads are caused mainly by the following reasons:

1) The use of complicated design and maintenance procedures adopted from developed countries.

Tanzania is using adopted design methods from USA and European countries to design road pavements and these methods have been in use even for low volume roads. Not only the use of these methods lead to higher construction costs that can not be met by roads fund board money but also require cumbersome procedures and modern equipments that most road maintenance agencies 
at district level do not have.

As a result many district engineers decide to do temporary intervention maintenance to allow flow of traffic with a lot of guess or traditional procedures (non scientific methods). The uses of these temporary intervention maintenance methods never eliminate the problems of natural road pavement failure.

2) The increase of moisture content in soil exceeding optimum moisture content.

Water seepage and percolation through permeable soil have intense effect on the road performance. The moisture environment in which the road pavement operates is a major influence on its performance because the strength, stability and stiffness of the pavement materials and sub grade are critically dependent on the moisture content. If the native road soil gets moisture above optimum moisture content then its ability to carry stress is decreasing whereby with increase of moisture content it turns to plastic state then starts to flow and failure occurs.

3) Higher tire pressures and low total axle loading.

Due to both small number of available vehicles in rural areas and availability of vehicle models like Mitsubishi Fuso Fighter of 4 tons that can carry up to 10 tons (farm products) without exceeding total axle loading in weigh bridges, consequently, most of the vehicles passing rural roads are not only overloaded in terms of carrying capacity but also have very higher tyre contact pressure. The current prevailing tyre contact pressure is estimated to be between $900-1000 \mathrm{kPa}$ which is higher than those used on key road performance experiments, such as the AASHTO road test of $500 \mathrm{kPa}^{5}$. Higher tyre pressures have big effect on the surface of the pavement and to places where there is steep grades, poorly drained area where there is moisture sensitive soils and low strength material.

From Figure 1, we can see that at $0 \mathrm{~cm}$ depth vertical stresses are higher but reduce with increase in depth [6].

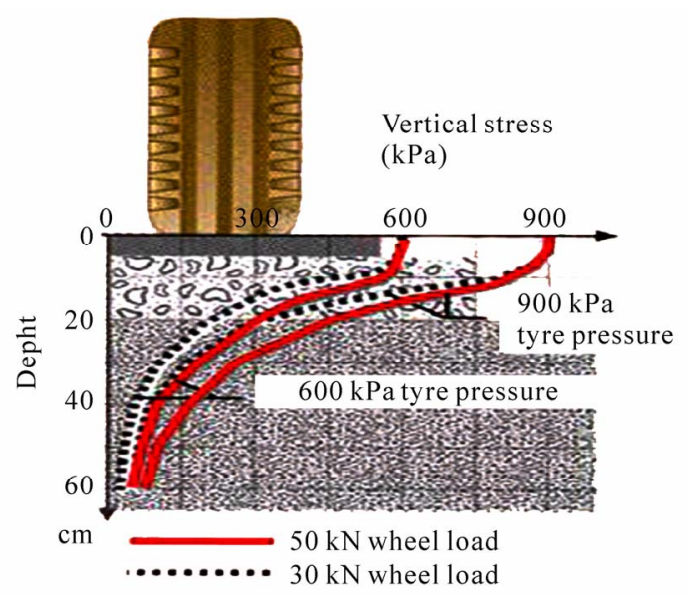

Figure 1. Showing stress distribution from tyre wheels at $500 \mathrm{kPa}, 600 \mathrm{kPa}$ and $900 \mathrm{kPa}$.
This paper presents the use of lime to change the engineering properties of native soils to be able to gain low plasticity, higher compressive soil, less permeability or percolation, higher tensile strength and reducing shrinkage and swelling.

\section{Experiments and Procedures}

Lime has a number of effects when added into soil which includes soil modification and soil stabilization [7]. Lime modification is a chemical change in which clay soils is transformed into friable, workable and compactable material. Lime stabilization occurs in soils containing a suitable amount of clay and the proper mineralogy to produce long-term strength, permanent reduction in shrinkage, swelling and soil plasticity with adequate durability to resist the detrimental effects of prolonged soaking.

Preliminary site soil investigation shows that the soil from Ngara district qualifies for both lime modification and stabilization. Detailed investigation is being undertaken now at China University of Geosciences.

The process of soil modification happens after initial mixing in which the calcium ions from lime will displace water, aluminum, iron and other ions from clay soil. The soil becomes friable and granular, making it easy to work and compact. At this stage of chemical reaction, not only the plasticity Index of soil decreases but also its tendency to swell and shrink.

The Figure 2 shows lime modified soil is friable, easier to handle, have low plasticity and can be easily compacted as compared to untreated soil.

Lime stabilization chemically changes clay soils into the following benefits of engineering properties of soil:

1) Reducing shrinkage and swell characteristics of clay soils.

2) Increase unconfined compressive strength by as much as 40 times.

3) Substantially increases load bearing capacity values as measured by such tests as CBR, R-value, Resilient

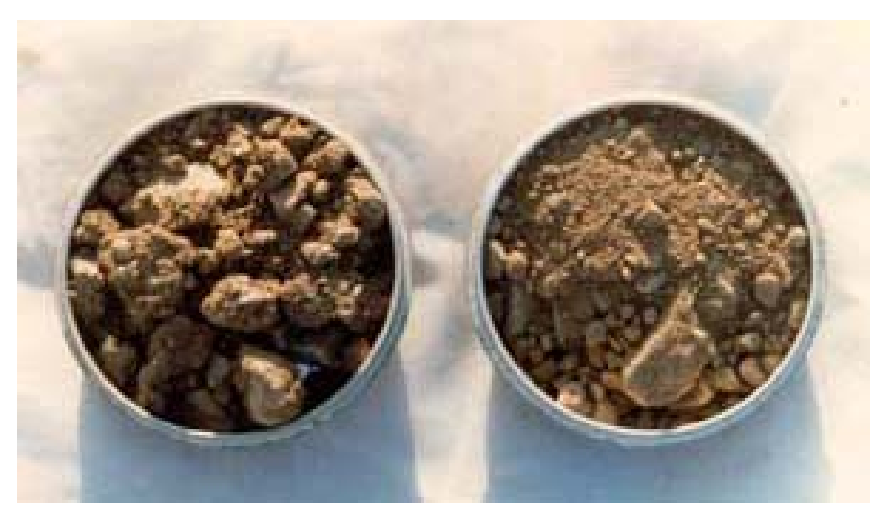

Figure 2. Left hand side shows clay soil without lime while right hand side shows soil with lime. 
Modulus, and the Texas Triaxial tests.

4) Develops beam strength in the stabilized layer and greatly increases the tensile or flexural strength.

5) Creates a water resistant barrier. Impedes migration of surface water from above and capillary moisture from below; thus helping to maintain foundation strength.

The process of lime stabilization is taking part by particles of clay soils breakdown after the rise of $\mathrm{pH}$ value of soil to at least above 10.5, which is the results of mixing adequate quantities of lime and water in the soil. Silica and alumina are released from the soil and reacts with calcium from the lime to form calcium-silicate-hydrates $(\mathrm{CSH})$ and calcium-aluminates-hydrates (CAH). CSH and $\mathrm{CAH}$ compounds form the matrix that contributes to the strength of lime-stabilized soil layer. At a time this matrix is forming, the soil is transformed from its highly expansive to a more granular, relatively impermeable material that can be compactable into layers with significant load bearing capacity.

The pozzolanic reaction creates new material that is permanent, durable, resistant to cracking, and significantly impermeable. The structural layer formed is both strong and flexible.

The Figure 3 shows the increase in CBR with reduction in optimum moisture content for lime treated soil [8] Ngara rural native soil roads are basically facing the

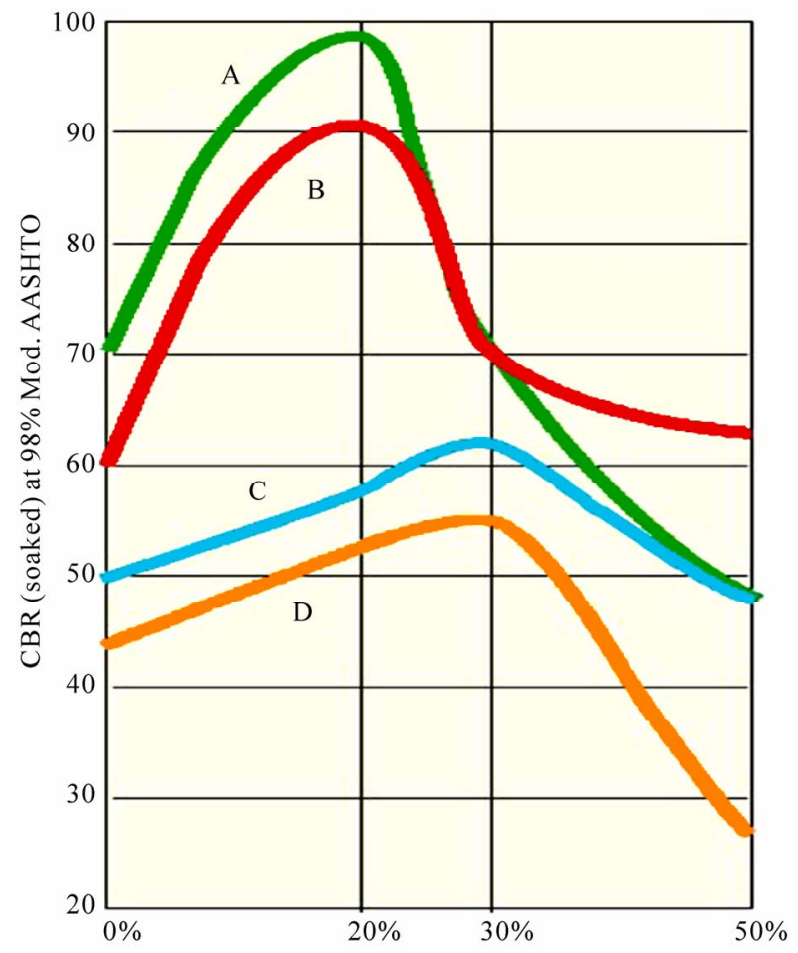

Figure 3. Sample A is soil stabilized with lime while sample C without lime and sample B is stabilized with lime while sample $D$ is native soil without lime. Sample $A$ and $C$ were taken from same source while Sample B and D also were taken form same source. following engineering problems:

1) Lack of higher shear strength and stiffness (instability).

2) Soil strength is so sensitive to the effect of moisture.

3) Lack of higher compressive strength.

4) The soil has higher values of plasticity index.

To understand the effect of lime on solving the road problems in Ngara we have to analyze the values of shear strength, resilient modulus and moisture resistance of typical lime stabilized soils.

\section{Results}

Based on AASHTO method T 294-94 and ASTM method D 5102 the soil properties and testing results are presented in Table 1.

The effect of molding moisture content and compaction on compressive strength of soil can determine well the moisture resistance of the soil. Below are the results from national lime association of USA showing the effect of molding moisture content of similar clay soils to Ngara soil.

\section{Discussion of the Results}

The test results from table 1 demonstrate the following to Ngara rural roads:

1) There is a good reaction of each soil with lime and an improvement in unconfined compressive strength.

2) There is structural improvement provided by increase in shear strength and resilient properties.

3) There is considerable reduction in plasticity Index of soil mixed with lime.

The test result from Table 2 illustrates two things:

1) strength and modulus values are highly sensitive to molding moisture content

2) Stabilization not only improves strength and stiffness values but also reduces the sensitivity of strength to the effects of moisture.

\subsection{Leaching of Lime}

Life expectancy of soil stabilized road varies depending on degree of stabilization and weather conditions. Some studies claim that for lower percentage of lime and if not protected from moisture (unpaved roads), the lime can leach out of the treated soil and soil will regain the properties of the untreated material. This leaching process has been observed in projects after 5-12 years or more. For higher application rates associated with soil stabilization, lime is bound to the soil particles through pozzolanic reactions that occur and is not susceptible to leaching. Therefore, lime stabilization of unpaved roads can per- 
Table 1. Shows the summary of unconfined compressive strength (ASTM D 5102) and Resilient moduli (AASHTO T 294-94) Testing.

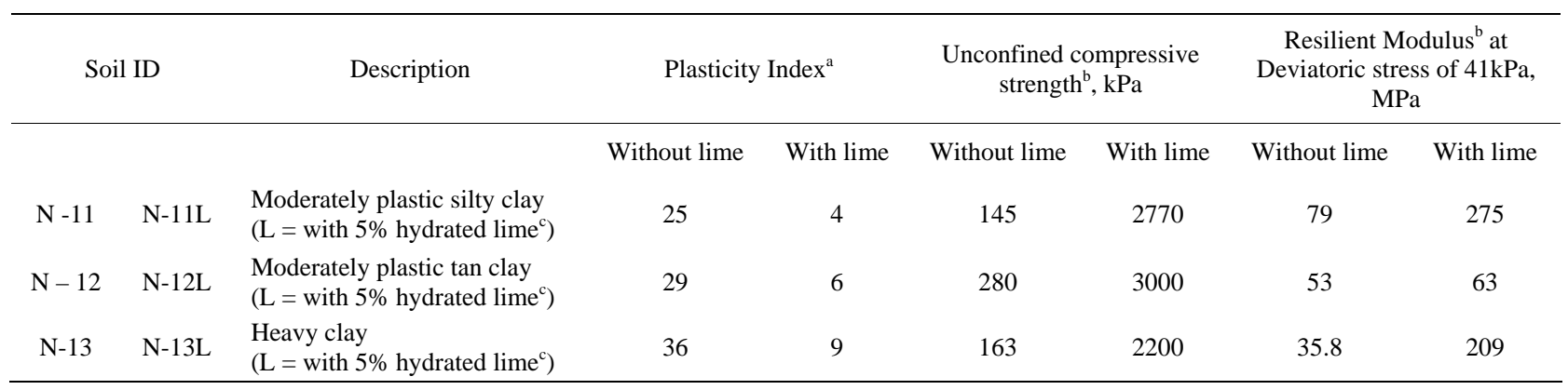

${ }^{\mathrm{a}}$ Determined after 24 hours of mellowing for stabilized soil; ${ }^{\mathrm{b}}$ All soil cured for 7 days at $400 \mathrm{Cin}$ plastic bags filled with water and subjected to capillary soak prior to strength testing; ${ }^{\mathrm{C}}$ The optimum lime demand for each soil was determined using the ASTM D $6276 \mathrm{pH}$ test.

Table 2. Shows the effect of compaction Energy and molding moisture content on unconfined compressive strength.

\begin{tabular}{cccccccccc}
\hline \multicolumn{1}{c}{ Soil ID } & \multicolumn{1}{c}{ Unconfined Compressive Strength, modified compaction Energy, kPa } & \multicolumn{2}{c}{$\begin{array}{c}\text { Unconfined Compressive } \\
\text { strength, Standard } \\
\text { compaction Energy, kPa }\end{array}$} \\
\cline { 3 - 9 } & & \multicolumn{2}{c}{ 1\% below optimum } & Optimum moisture content & $1 \%$ above optimum & Optimum \\
\hline Without lime & With lime & Without lime & With lime & Without lime & With lime & Without lime & With lime & Without lime & With lime \\
N-11 & N-11L & 225 & 2725 & 280 & 2980 & 120 & 2235 & 124 & 1395 \\
N-12 & N-12L & 140 & 2458 & 145 & 2765 & 70 & 1935 & 105 & 1293 \\
N-13 & N-13L & 155 & 2150 & 160 & 2275 & 85 & 1820 & 50 & 1195 \\
\hline
\end{tabular}

form well during the entire period of design life serving road users at satisfactory level in the social economic level of Tanzania.

The design life of unpaved rural road is 10 to 15 years as recommended by SADC and TRL.

\section{Conclusions and Recommendations}

1) From the preliminary investigation, results from similar research and laboratory results, the native clay soil of Ngara can be stabilized by lime to increase shear strength, unconfined compressive strength, modulus values, stiffness values and reduction in plasticity index to withstand tire pressure and axle loading without excessive deformation at relatively lower cost.

2) The unpaved native soil roads should have higher compressive strength materials at the top (about $20 \mathrm{~cm}$ thick) to overcome the problem of higher tire pressure. A layer caused by lime stabilized material can serve the purpose.

3) Further investigation is required to outline road maintenance procedure and design based on southern countries local soil condition and composition instead of adopting complicated methods from northern countries.

4) Road design consideration can also be incorporated to ensure proper drainage of run off water.

\section{Acknowledgements}

This research is supported by the Chinese Government Scholarship Council.

\section{References}

[1] Road Fund Board of Tanzania. http://www.roadfund. org.tz

[2] Tanzania National website. http://www.tanzania.go.tz.

[3] SADC, “Guideline on Low Volume Sealed Roads,” 2003.

[4] Ngara, "District Council Authority-Works Department," 2008. http://www.ngaradc.com.

[5] AASHTO, “The AASHTO Road Test: Pavement Research,” ERB special Report 61E, American Association of State and Highway Officials, Washington, 1962.

[6] J. M. Johnsen and P. K. Senstad, "Effects of Tire Pressures on the Flexible Pavement Structure - A Literature Survey," Norwegian Road Research Laboratory, Oslo, No. 62, 1992.

[7] National Lime Association, "Lime Treated Soil Construction Manual: Lime Stabilization \& Lime Modification,” 2004. http://www.lime.org/AMDTP.pdf

[8] N. Little Dallas, "Evaluation of Structural Properties of Lime Stabilized Soils and Aggregates,” 2000. 